\title{
PRÁTICAS DE CONSUMO CONSCIENTE EM CAMPANHA PUBLICITÁRIA DE ORGANIZAÇÃO COMPETITIVA
}

\author{
Edson Roberto Scharf \\ Doutor em Marketing/Branding \\ FURB Universidade de Blumenau \\ Blumenau - Santa Catarina - Brasil \\ artigoes@gmail.com \\ Josiane Fernandes \\ Doutoranda em Administração \\ LU Lancaster University Management School Bailrigg - Lancaster \\ Reino Unido \\ jozibnu@gmail.com \\ Juarez Perfeito \\ Doutorado em Ciência Econômicas e Empresariais \\ Centro Universitário Municipal de São José \\ São José- Santa Catarina - Brasil \\ juarez.perfeito@gmail.com \\ Michelle Karina Dapper \\ Graduanda em Tecnologia em Marketing \\ FURB Universidade de Blumenau \\ Blumenau - Santa Catarina - Brasil \\ michellekarina16@gmail.com
}

\section{RESUMO}

Este estudo tem por objetivo analisar práticas de consumo consciente e discussões acerca destas, presentes em campanha publicitária de uma instituição financeira à luz da proposição de interesses temáticos desenvolvida por Arnould e Thompson (2007). O percurso analítico vai da identificação de elementos expressos nas mensagens até o entendimento dos seus elementos sígnicos. É qualitativa no método. A técnica analítica escolhida é a Análise Crítica do Discurso (ACD). Como resultado, se demonstrou que as mensagens veiculadas na propaganda do banco contêm discurso sobre o consumo consciente, refletindo ações concretizadas ou não - da vida dos indivíduos. Também se encontrou evidências de que aspectos da Consumer Culture Theory estão presentes na ação publicitária analisada.

Palavras-chave: Análise crítica do discurso. Consumo consciente. Consumer culture theory. Propaganda. Responsabilidade social corporativa.

\section{CONSCIOUS CONSUMPTION PRACTICES IN ADVERTISING CAMPAIGN FROM THE COMPETITIVE ORGANIZATIONS}

\begin{abstract}
This study aims to analyze the practices of conscious consumption and discussions about that and lifestyle in the bank advertising campaign. The analytical course will identify the elements expressed in the messages into the understanding of their signical elements. It is the qualitative regarding the method. The data collection strategy is documentary source, and the selected analytical technique was to Critical Discourse Analysis (CDA). As a result, it was shown that the messages conveyed in bank advertising campaign contain the spirit of the streets, that people already take for actions - accomplished or not - in their lives. The originality of the study is translated for being the first study evaluating the discourse of advertising messages of a Brazilian bank with the CDA technique.
\end{abstract}

Key words: Advertising; Conscious consumption; Consumer culture theory; Corporate social responsibility; Critical discourse analysis. 


\section{INTRODUÇÃO}

O estudo sobre consumo tem produzido um fluxo corrente de trabalhos voltados a elementos de naturezas sociocultural, experiencial e simbólica. Nos últimos anos, porém, transformações mais profundas ocorreram na relação empresa-mercado-consumidor, segundo Kalra e Soberman (2010), como novas mecânicas de definição de budget, atuação de concorrentes em segmentos diversos ou formatos inovadores de comunicação, levando a outras frentes de pesquisa.

Neste panorama, duas vertentes de comunicação se distanciaram entre si, segundo Agrawal e Duhachek (2010), a saber a propaganda comercial e a propaganda institucional. Mensagens comerciais, em que o desenvolvimento criativo racional se dá em conexão com o emocional, objetivam a venda de um produto (lançamento de nova versão, horários alternativos para atendimento no varejo ou promoção em data comemorativa, por exemplo). Segundo Bridges, Keller e Sood (2000), esta propaganda tem o importante papel de estimuladora dos impulsos de compra, estando o consumidor no centro das relações empresamercado-consumidor a partir de suas individualidades e desejos. Mensagens de teor institucional, por sua vez, geralmente apresentam aspectos emocionais e buscam a preferência do consumidor para a marca, segundo Bridges et al. (2000), valorizando elementos que não tenham o papel principal de venda (tais como investimento em pesquisa e desenvolvimento, adoção da responsabilidade social corporativa - doravante CSR, do original em inglês Corporate Social Responsibility - ou competência técnica da equipe).

A opção por uma das vertentes depende dos objetivos de comunicação definidos pelo anunciante. Dolbec e Fischer (2015) entendem que as forças econômicas do momento, as alterações de comportamento do comprador e o interesse no reposicionamento ou sustentação da marca são os principais motivadores pela escolha de um ou outro tipo de mensagem publicitária.

Algumas organizações assumem posturas de comunicação que dialogam com o consumidor sem exercer uma condição de entidade vendedora, ainda que sua sobrevivência dependa da obtenção de lucro com a venda de bens e serviços. Elas comunicam aspirações, expectativas e experiências que reflitam a vida das pessoas. Para estas empresas, o capital envolvido na aquisição de automóveis, moda, decoração, saúde ou conhecimento é construído por signos múltiplos. A capacidade de resiliência das organizações em relação a esses anseios contemporâneos dos indivíduos influenciou a criação de novos formatos de mensagem e, mais especificamente, novos significados inclusos nestas mensagens.

A aquisição de empresas por grandes corporações globais, a comunicação em massa, a individualidade das decisões de compra e a busca pelo desenvolvimento de uma identidade própria e uma coletiva, são questões presentes no estudo do consumo e dos estilos de vida. A partir de perspectivas teóricas sociais, simbólicas, experienciais e ideológicas do consumo, Arnould e Thompson (2005) apresentaram o conceito de Consumer Culture Theory (doravante, CCT), como forma de explicitar a relação entre os significados culturais, as ações de consumo e o mercado. De maneira complementar ao consumo abordado na CCT, o consumo consciente prega a compra e o uso de bens e serviços para atendimento de necessidades enquanto busca minimizar a degradação ambiental e social.

Características de campanhas publicitárias têm sido descritas por pesquisas no campo do Marketing, a exemplo de trabalhos de autores como Morgan e Stoltman (2002), Toomey e Francis (2013) e Whiting e Williams (2013). No entanto, é pouco estudado o esforço mercadológico das empresas que veiculam comerciais que defendem o consumo consciente em suas mensagens. Como a propaganda de CSR deve ser desprovida de elementos de consumo tais como os conhecemos, segundo Prasad e Holzinger (2013), este estudo pretende identificar se estas iniciativas empresariais estão isentas de intuito comercial ou se, apesar de ser uma ação em prol do desenvolvimento sustentável, atributos de consumo continuam presentes na campanha.

Neste sentido, o objetivo deste estudo é analisar a propaganda em iniciativas para o consumo consciente de uma instituição financeira, à luz da estrutura de interesses temáticos de Arnould e Thompson (2007). Esse trabalho assume uma abordagem sociocultural, com a interpretação dos dados qualitativos a partir dos conceitos de consumo consciente e CCT.

\section{FUNDAMENTAÇÃO TEÓRICA}

Os conceitos a seguir buscam situar o leitor em relação ao consumo consciente e ao conteúdo das mensagens publicitárias. 


\subsection{O consumo consciente}

A expansão da produção capitalista, especialmente algumas décadas depois do fim da segunda Grande Guerra, exigiu a construção de novos mercados e o direcionamento das massas consumidoras. Consumo, segundo McCracken (2012), é uma manifestação cultural de todos os seres humanos, tanto para manutenção de necessidades básicas como para satisfação pessoal ou tradução das suas identidades e seu poder. Consumidores, segundo o autor, usam os significados dos bens de consumo para criar e sustentar estilos de vida, por meio do consumo responsável. A invasão no consumo, nas atividades de lazer, arte e cultura, ocorre de tal maneira, segundo Featherstone (1995), que a dominância do valor de troca suprime a memória do valor de uso original dos bens. Os produtos, segundo o autor, são conectados a um amplo cabedal de associações e ilusões, muito bem feito pela propaganda. Skarmeas e Leonidou (2013) defendem que atualmente ocorre uma reação ao caráter de hegemoneização da mercantilização, com a intenção de tornar as coisas preciosas e de que bens e serviços possuem significados que transmitem expressões de autenticidade dos indivíduos.

Consumo consciente é a mola propulsora desta nova sociedade, segundo Morsing (2006), que sai do hiperconsumo para atividades que preservem a cultura pessoal e a do seu grupo, com o produto sendo um veículo que sustenta a sua identidade. $\mathrm{O}$ conceito de consumo consciente sugere uma adequação no comportamento do consumidor, se preocupando com o ambiente e englobando, ainda, variáveis coletivas e responsáveis no ato do consumo, levando em consideração os impactos provocados por ele. Fournier (1998) aponta para o consumo consciente como padrões de consumo pelos quais a compra e o uso de bens e serviços atendam às necessidades das pessoas ao mesmo tempo em que haja a minimização da degradação ambiental e social, como se fosse uma contribuição voluntária para garantir a sustentabilidade da vida. Morsing (2006) sugere que consumo consciente é considerado o ato de compra de bens e serviços praticado por um indivíduo, que conta com o equilíbrio entre satisfação pessoal, possibilidades ambientais e efeitos sociais do seu ato. Nair e Ndubisi (2011) complementam afirmando que o consumidor sabe da sua responsabilidade como ator na sociedade quando adota o consumo consciente por compreender que há um conjunto de atores sociais envolvidos na aplicação deste conceito. Para Skarmeas e Leonidou (2013), o consumo consciente não é apenas um ato, mas um estilo de vida voltado às responsabilidades sociais e ambientais como forma de adotar práticas sustentáveis no longo prazo.

Contribuem com essa proposição as organizações que adotam iniciativas CSR, uma vez que trabalham para o bem-estar coletivo em suas ações sociais e econômicas. O consumo consciente pode ser um dos resultados alcançados ao se fazer, segundo Kashdan e Breen (2007), atividades relacionadas com a responsabilidade social corporativa. A consciência no consumo é parte positiva do comportamento de um novo consumidor, ligado a questões ambientais, sociais e econômicas, conforme os autores.

Neste sentido, Miller (1995) advoga que há um comportamento atual de preocupação com presentear a quem desperta afeto com mercadorias específicas, atentando para marcas específicas, como um jeans da Gap ou um tênis da Nike, ao invés de tradicionais presentes como flores ou joia. O autor sugere que este comportamento é de caráter consciente, uma vez que traduz não a intenção de ostentar ou preencher algum vazio interno, mas antes caracteriza a valorização da sensibilidade demonstrada pelo indivíduo sobre a natureza da pessoa com a qual se relaciona. Na visão complementar de Campbell (2006), é um indício das transformações ocorridas na cultura contemporânea.

Alguns autores, tais como Morsing (2006), e Prasad e Holzinger, (2013), concluem que o entendimento atual de CSR está voltado para quatro aspectos principais: a busca de objetivos corporativos que produzam lucros no longo prazo; o uso do poder de negócio de uma forma responsável; a integração de demandas sociais no seu planejamento; e a contribuição para o bem da sociedade. Quanto a este último aspecto, que forja um conceito mais próximo do consumo consciente, há duas visões não excludentes, embora traçadas por caminhos dicotômicos. De um lado, alguns autores, tais como Cross (2000) e Campbell (2006), sugerem que os prazeres emocionais relacionados à busca ou afirmação de status e a busca de bemestar permanente não são os mais frequentemente desejados pelos consumidores contemporâneos. De outro lado, alguns autores, tais como Lasch (1983), Bauman (2001) e Baudrillard (2009), enfatizam a existência desse tipo de motivação para consumo no momento presente.

Se para a European Commission (2014) as organizações devem ter em andamento um processo para integrar as preocupações sociais, ambientais, éticas, de direitos humanos e dos consumidores, para que possam atender plenamente a condição de CSR, para Prasad e Holzinger (2013), os esforços de Marketing com iniciativas dessa natureza podem ser um exemplo de voo corporativo de responsabilidade, uma vez que a ativa representação dos stakeholders internos e externos se apresentam como uma promissora garantia de 
que múltiplas perspectivas serão ouvidas e consideradas nas decisões de Marketing. Ou seja, a oferta de bens e serviços é desenvolvida e comunicada visando o consumo consciente, posto que este é essência da CSR. Segundo McWilliams e Siegel (2001), são estas iniciativas que trazem benefícios sociais para além dos interesses empresariais e requeridos pela lei.

Segundo Skarmeas e Leonidou (2013), o entendimento deste novo comportamento de consumo, em que o indivíduo não tem a intenção de realçar o sentimento de ostentação, mas de demonstrar a afeição por si e pelos outros, ameniza a constante afirmação de que o interesse pelo consumo decorre da presença de um materialismo característico da sociedade contemporânea. Corrobora Campbell (2006), ao afirmar que é comum o indivíduo usar a interação com produtos e marcas com o intuito de se conscientizar a respeito das suas preferências mais fortemente do que para buscar aprovação social.

Campbell (2006) aponta outro aspecto importante decorrente do exercício do consumo consciente, a denominada de "ânsia de singularização". Ela é a oposição à padronização dos produtos de massa, em que o indivíduo deseja bens e serviços compreendidos como únicos, singulares, uma expressão da individualidade e autenticidade do comprador.

\subsection{O conteúdo das mensagens e a CCT}

Produtos têm sido adquiridos pelo significado que transmitem para o eu e para o grupo, mais do que pelos benefícios funcionais. Para representar os significados desejados pela organização, marcas são trabalhadas e as mensagens da propaganda são aliadas na configuração desse apelo.

O discurso de que o consumo é decorrente do egoísmo humano tem sido bastante empregado. Contudo, segundo McCracken (2012), este discurso negligencia a importância dos produtos adquiridos e os significados vinculados a eles e que auxiliam a definir a identidade das pessoas. Nomes de marca ou desenhos constituem apenas sinais materiais amorfos até que a marca crie sua história pela soma de ideias e experiências dos consumidores com o produto ao longo do tempo. Segundo Holt (2005), a propaganda aparece como difusora destes ideais da marca por palavras, sons e imagens, criando atalhos mentais para incentivar o uso de algum bem ou serviço por meio da exploração de emoções, inseguranças e anseios.

Baudrillard (2009) defende que a lógica social do consumo é estruturada como uma linguagem, pois não se trata mais de uma apropriação individual do valor do uso dos produtos nem da satisfação com este uso, mas a produção e a manipulação dos significantes sociais. Para o autor, o consumo precisa ser entendido como um processo de comunicação, com a apropriação dos produtos e dos signos que os diferenciam, e como um eficiente processo de classificação e diferenciação social.

Por causa da diversidade de códigos e das competências distintas de emissores e destinatários, a interpretação da mensagem assume uma complexidade que pode ter variados significados. No entender de Fairclough (1995), um código é um sistema convencionado social e culturalmente pelos sujeitos de uma determinada cultura. A ênfase deixa de ser unicamente no polo emissor, passando a adquirir relevância justamente a dinâmica existente entre emissor e destinatário. Os significados, para McCracken (2003), são formados no interior das culturas e baseados nos recursos disponíveis, tais como valores e hábitos. O autor sugere que todas as formas de consumo são culturalmente movidas de acordo com modos de vida significativos, por meio dos quais as pessoas produzem e reproduzem culturas e relações sociais.

Nesta discussão, o uso das metáforas se insere como parte importante do processo de comunicação mercadológica, mais especificamente no entendimento dos discursos produzidos nos contextos da propaganda. Para Bridges et al. (2000), metáfora é uma expressão linguística particular ou excertos de linguagem que atuam com a introdução de insights sobre a compreensão de determinada situação. Morgan (2011) sugere que as metáforas são compreendidas como artifício para embelezar o discurso, implicando um modo de ver a situação que permeia a maneira como entendemos o mundo real.

Segundo Askegaard e Linnet (2011), a partir da década de 1960 o comportamento do consumidor obteve grande interesse de estudo. Antes fortemente centrada na produção, o trabalho científico começou a incorporar o consumo, principalmente com o aumento da concorrência movido pela globalização. Para MacInnis e Folkes (2010), três são as perspectivas assumidas no estudo do comportamento do consumidor: a Behaviorial Decision Theory, a Information Processing e a Consumer Culture Theory. Assim, o consumo materializa os aspectos culturais incorporados pelo indivíduo, segundo Kozinets (2001), tomando por base a interação das suas particularidades com o contexto sociocultural do ambiente em que se encontra.

A partir do conceito de cultura e de estudos sobre dimensões simbólicas, experienciais e ideológicas do consumo, é apresentada, por Arnould e Thompson (2005), a Consumer Culture Theory (CCT) que trata das relações dinâmicas entre as ações dos consumidores, o mercado e os significados culturais. A conjunção 
da cultura e do consumo que contempla um conjunto de perspectivas teóricas sobre o comportamento do consumidor, teve seu início na década de 1980, com os trabalhos de Levy (1981) e Holbrook e Hirschman (1982).

A CCT explora a heterogeneidade da distribuição de significados e a multiplicidade de clusters culturais imbricados. Para Arnould e Thompson (2005), a cultura de consumo desenha um arranjo social em que as relações entre cultura vivida e recursos sociais e entre formas significativas da vida e recursos materiais de que dependem, são mediadas pelos mercados. No entendimento de diversos autores, como Arnould e Thompson (2005) e Askegaard e Linnet (2011), a CCT tem como aspectos essenciais o significado social, a influência sócio-histórica e a dinâmica social que, juntos ou em momentos separados, formam a experiência do consumidor e sua identidade. Por sua vez, Featherstone (1995) buscou entender as associações entre cultura de consumo e pós-modernidade, defendendo que o consumo de prestígio desenvolve sonhos por meio da simbologia. Já Slater (2001) apresenta a cultura de consumo como um conjunto de processos e ideologias, não atribuindo sentido aos objetos de consumo e sim na construção de culturas individualistas. Trabalhos mais recentes de pesquisa, segundo Dolbec e Fischer (2015), tratam de entender como se formam e se transformam as dinâmicas de mercado.

Por seu lado, Arnould e Thompson (2007) apresentam um desenho esquemático de quatro interesses para explicar a CCT. Composto de padrões sócio-históricos de consumo; culturas de mercado; ideologias do mercado midiático de massa e estratégias interpretativas dos consumidores; e projetos de identidade do consumidor, se propõem a orientar estudos da área, balizando novas frentes de entendimento sobre o consumo. Os autores defendem o conceito de CCT para explicar e compreender a relação posta de maneira dinâmica entre os significados culturais, as atividades de consumo e o mercado.

Segundo Arnould e Thompson (2007), os padrões sócio-históricos de consumo abordam a formação de consumo por classe, etnias, gêneros e outras categorias sociais; o consumo sob variadas condições de recursos culturais; e institucionalização e reprodução das relações de poder nas hierarquias socioeconômicas. Para os autores, as culturas de mercado contemplam as dinâmicas socioculturais envolvidas nas comunidades de marca; as comunidades de fãs e subculturas de consumo; e o mercado como mediador das relações sociais.

Por último, os autores defendem que os projetos de identidade do consumidor abrangem imagem e representação do eu, diversidade entre os gêneros, distinções simbólicas, contradições culturais e dimensões experienciais do consumo.

Se para Solomon (2008), o consumo dá forma aos aspectos culturais do indivíduo pela interação das suas particularidades com o contexto sociocultural do ambiente em que ele se encontra envolvido, para Arnould e Thompson (2005), a cultura de consumo trata de um ajuste social por meio dos mercados, em que há relação entre a cultura vivida e o recurso social, entre os significados da vida e do simbólico e os recursos materiais necessários. Neste sentido, os autores defendem que a semiótica cultural de determinado grupo ou sociedade é atribuída a bens e serviços incorporados ao cotidiano dos indivíduos e é mediada pelo mercado. As ideologias do mercado midiático de massa, no entender de Arnould e Thompson (2007), se compõem de representações materiais, discursivas e imagéticas das ideologias consumistas no mercado; do uso da mídia pelos consumidores e ações contrárias aos códigos hegemônicos; e da influência da globalização nas mídias e no consumo.

\section{MÉTODO}

Esse estudo foi classificado como exploratório e de abordagem qualitativa. O caráter exploratórioqualitativo se justifica quando o estudo envolve um fenômeno complexo e multifacetado, segundo Malhotra (2010). A teoria teve a função de direcionar a pesquisa, sendo complementada com uma reflexão após a descrição das análises realizadas. Portanto, se abriu o estudo com a literatura, se procedeu a análise dos resultados alcançados e se finalizou com uma discussão a partir da literatura.

A fase de análise dos resultados adquiriu um contorno comparativo, ao se defrontar os comerciais com os interesses temáticos propostos por Arnould e Thompson (2007). O desenho esquemático apresentado pelos autores contempla quatro frentes temáticas: padrões sócio-históricos de consumo; culturas de mercado; ideologias do mercado midiático de massa e estratégias interpretativas dos consumidores; e projetos de identidade do consumidor.

O objeto de estudo foi a campanha publicitária do banco Itaú denominada \#issomudaomundo, veiculada a partir de julho de 2013, na televisão e na internet, em um total de 13 comerciais (alguns comerciais foram veiculados somente na internet). A unidade de análise foi delimitada ao comercial que 
lançou a campanha (de título Educação, Cultura e Bike, veiculado pela primeira vez em 15 de julho de 2013) e ao comercial que a finalizou (Suas Escolhas, com a primeira veiculação em 4 de fevereiro de 2015). Ambos os comerciais foram veiculados em sítio próprio e no repositório do Youtube e, posteriormente, na TV de sinal aberto.

A plataforma criada para absorver toda a campanha \#issomudaomundo é formada por quatro frentes: educação, cultura, mobilidade urbana e esporte. O nível de análise correspondeu às estratégias de comunicação publicitária empregadas, incluindo mensagens, apelos e recursos de sintaxe. Esse estudo utilizou um desenho de amostragem intencional, segundo os preceitos de Miles e Huberman (1994). Todos os comerciais estão disponíveis no sítio do repositório Youtube.

O método de coleta de dados empregado foi a análise documental e envolveu a identificação, verificação, organização, leitura e apreciação do conteúdo (texto, som e imagem) do material publicitário selecionado em mídia eletrônica da TV (canais de sinal aberto e fechado) e da internet (especificamente no repositório Youtube). Os dados foram interpretados com a análise textual (descrição de informações e metáforas), com a análise processual (textos e práticas discursivas) e com a análise social (efeitos socioculturais da prática discursiva), conforme Fairclough (1995).

Inicialmente, se fez uma leitura flutuante dos comerciais, em que os pesquisadores buscaram compreender a linha conceitual e a estratégia de raciocínio criativo. Nesta etapa, os pesquisadores assistiram três vezes a cada comercial. Em seguida, o comercial foi decupado em cenas com proximidade de ideia para se proceder o entendimento das - possíveis - várias histórias presentes dentro de cada comercial. Foi iniciada a descrição das cenas, sem a interpretação das mesmas. As descrições de som e imagem foram apresentadas, discutidas e verbalizadas, formando a análise textual. Os autores, então, procederam a busca por elementos complementares ao filme, principalmente documentação referente à criação, produção e implementação do comercial. Ao final, com o conjunto de informações compartilhado, se assistiu novamente aos comerciais por duas vezes para confirmação das considerações discutidas, e se constituiu a análise processual. Por último, os autores iniciaram ampla discussão sobre os elementos anteriormente redigidos, com o objetivo de dialogar com a literatura de Marketing, Estratégia, Linguagem e demais áreas que pudessem aperfeiçoar o estudo. Após esta etapa, se assistiu aos comerciais mais uma vez, dando início à redação da análise social.

As análises foram realizadas com o uso da técnica Análise Crítica do Discurso (ACD). A ACD envolve linguagem e discursos construídos ou condicionados socialmente. Conforme Fairclough (1995; 2001), discurso é uma prática de significação do mundo que constrói identidade social, relação entre pessoas e sistemas de conhecimento. A ACD vê o discurso como noção integradora de três dimensões, segundo Magalhães (2001): o texto, a interação/prática discursiva e a ação social/prática social. Para Chouliaraki e Fairclough (1999), o discurso figura em práticas sociais por meio dos significados e dos elementos que compõem ordens deste discurso, a saber: gêneros (tipo de linguagem ligado a uma atividade social particular), discursos (tipo de linguagem usada para construir algum aspecto da realidade de uma perspectiva particular) e estilos (tipo de linguagem utilizado por uma categoria particular de pessoas).

A técnica de análise teve como arquitetura estrutural aquela aplicada por Scharf e Sarquis (2014). Assim, na análise textual, foi verificado o controle interacional da estrutura textual e os elementos constituintes do comercial, na análise processual foram avaliadas as dimensões interpretativa e de natureza textual da produção e na análise social foi verificada a prática social e de eventos comunicativos. Para melhor entendimento, ver Tabela 1. Segundo o que defendem Chouliaraki e Fairclough (1999) e Fairclough (2001), o método empregado permite destacar os aspectos publicitários desejados. 
Tabela 1 - Tipos de análise adotados, a partir da técnica ACD

\begin{tabular}{|l|l|l|l|}
\hline Tipo de análise & Procedimento de verificação & \multicolumn{1}{c|}{ Procedimento de análise } \\
\hline Textual & $\begin{array}{l}\text { O controle interacional da } \\
\text { estrutura textual, com descritivo } \\
\text { das ações publicitárias e seus } \\
\text { elementos }\end{array}$ & $\begin{array}{l}\text { Estratégias de comunicação, características da } \\
\text { construção da campanha, coesão do texto e da imagem, } \\
\text { padrões discerníveis na estrutura das peças } \\
\text { publicitárias e palavras com significados culturais } \\
\text { diferentes }\end{array}$ \\
\hline Processual & $\begin{array}{l}\text { As dimensões interpretativa e } \\
\text { de natureza textual da } \\
\text { produção, com interpretação } \\
\text { das ações publicitárias }\end{array}$ & $\begin{array}{l}\text { Interdiscursividade, contexto, coerência, discursos e } \\
\text { representação dos discursos e implicações } \\
\text { interpretativas }\end{array}$ \\
\hline Social & $\begin{array}{l}\text { Discurso social e eventos } \\
\text { comunicativos, com reflexão } \\
\text { sobre as práticas adotadas }\end{array}$ & $\begin{array}{l}\text { Matriz social do discurso, relações entre práticas } \\
\text { sociais e discursivas, identificação de sistemas de } \\
\text { conhecimento, crenças e relações sociais }\end{array}$ \\
\hline
\end{tabular}

Nota. Fonte: Adaptado de Scharf, E. R. e Sarquis, A. B. Análise crítica do discurso na propaganda de lançamento do Citröen C3 Picasso. Revista Brasileira de Marketing, v. 13, n. 3, p. 36-48, 2014.

\section{ANÁLISE E RESULTADOS}

A seguir, são apresentadas as análises textual, processual e social para os comerciais de lançamento e de encerramento da campanha \#issomudaomundo.

\subsection{Análise textual}

O comercial de lançamento da campanha é o Educação, Cultura e Bike, principal vídeo da plataforma \#issomudaomundo (disponível no repositório Youtube, no endereço https://www.youtube.com/watch?v=wXuNqCVoz7U). Com duração de trinta segundos, foi veiculado também em canais de transmissão aberta e fechada, e no canal Banco Itaú O segundo comercial encerra a campanha estudada. De título Suas Escolhas (disponível no endereço https://www.youtube.com/watch?v=ix2AaUHXghM), tem duração de trinta segundos, sendo veiculado também em canais de sinal fechado. Ambos os comerciais adotam apelo criativo condizente com os trabalhos anteriores da instituição, com cenas curtas e recurso direto na contação de pequenas histórias cotidianas. A coesão de texto e imagem ocorre em função do uso de linguagem estética adotada nas principais redes sociais, com imagens rápidas, representação de uma ideia em poucos movimentos e textos exíguos ou inexistentes. Os padrões publicitários são discerníveis em relação aos comerciais de concorrentes ou outras organizações, pois são mantidas as características de linguagem das ações de comunicação anteriores e atuais, em vídeo ou impressas. A construção da campanha publicitária ocorre com os mesmos principais elementos constitutivos: cor predominante, logomarca em inserções incidentais, pessoas jovens, situações cotidianas, música em formato de versão e aspectos banais transformados em pequenos eventos.

\subsection{Análise processual}

No levantamento Marcas Brasileiras Mais Valiosas nas edições de 2014, 2015 e 2016, realizado pela Interbrand, consultoria mundial especializada em marcas, Itaú é a marca brasileira mais valiosa e bem avaliada, considerando fatores internos (clareza, comprometimento, proteção e capacidade de resposta) e fatores externos (autenticidade, relevância, diferenciação, presença, entendimento). Uma marca forte tem como suporte um complexo de ações de comunicação em plataformas variadas, segundo Whiting e Williams (2013). O banco Itaú, conjuntamente com a veiculação da campanha \#issomudaomundo no seu sítio eletrônico, esteve presente em outras mídias, como as TVs de sinal aberto e fechado, e em materiais de ponto de venda. Teve como principal objetivo estimular a consciência das pessoas, em um convite ao engajamento com as causas da empresa, a saber mobilidade urbana, educação, cultura e esporte, todas evidenciadas nesta campanha publicitária.

Para dar conta de atender ao que pede a $\mathrm{ACD}$ em relação à coerência do contexto e à representação dos discursos, se faz necessária uma avaliação sobre forma e conteúdo dos significados apresentados na campanha.

Do ponto de vista de forma, os comerciais foram produzidos em filme $35 \mathrm{~mm}$, ou seja, com qualidade superior ao que a gravação em vídeo pode alcançar. $\mathrm{O}$ uso de uma linguagem fotográfica em nível 
de película permite às pessoas rápida conexão com a qualidade de filmes já vistos nas salas de cinema, o que facilita o interesse pela mensagem e a relação com um produto distinto. Segundo Fairclough (1995), quem recebe a mensagem, não recebe apenas uma mensagem, mas um conjunto delas, pois os espaços de recepção são heterogêneos e multifacetados.

Do ponto de vista de conteúdo, seu contexto de aplicação se dá em um momento em que o mundo repensa seus hábitos. O consumo excessivo foi o precursor do consumo que substitui a simples relação socioeconômica por um valor de experiência, segundo Agrawal e Duhachek (2010). O discurso textual dos comerciais sugere que ações tomadas pelas pessoas no cotidiano mudam o mundo, como se a soma de cada atividade feita alterasse o curso do planeta. Isto é notado quando o roteiro assume uma linguagem ativa e questiona o telespectador sobre o que ele está escolhendo hoje, levando a pensar sobre que atividade saudável ele se permitirá, de qual evento cognitivo ele participará ou, ainda, de que interesses enriquecedores ele pretende ser protagonista.

Reside aqui outra das implicações que a presença do telespectador incute nos filmes: o de ator principal. Afinal, quando o anunciante divulga uma mensagem de inspiração para as pessoas, sem haver correlação com o fato de um banco ter como interesse principal a administração do dinheiro dos investidores e correntistas, a organização coloca quem ouve a mensagem no comando das ações, como alguém que deve tomar nas mãos as rédeas do seu destino, sem invocação explícita ao consumo. Em raros momentos são observadas alusões ao consumo de bens ou serviços nos comerciais analisados. Eventualmente, se pode argumentar que a ida ao cinema ou ao teatro ou mesmo a compra de uma bicicleta não pode prescindir de dinheiro. No entanto, a campanha \#issomudaomundo fala da sensação de poder tomar decisões que repercutam na melhoria do estilo de vida, como as citadas, e não na aquisição do bem ou do serviço por meio de crédito ofertado pelo banco.

Esse protagonismo é coerente com a ideia de Baudrillard (2009), para quem as pessoas buscam exaltar sua individualidade por meio do que consomem, comunicando ao mundo o que são, a que grupo pertencem, no que acreditam. Para um comercial de banco, são esperadas abordagens como a alusão a baixas taxas de financiamento ou a rapidez na aprovação de crédito. Nesta campanha institucional, porém, as mensagens evidenciaram o apelo emocional, sem ocupação explícita de venda e seus aspectos funcionais. $\mathrm{O}$ que fica aparente é o esforço da marca para ocupar um espaço na mente das pessoas como uma organização que tem responsabilidade com o seu meio, sabedora de sua importância como um ente na sociedade. Mesmo assim, ainda que evidências existam, é de se discutir sobre a real intenção do anunciante, visto que, ao final de um processo de comunicação, as organizações sempre controlam os seus investimentos para confirmar se os objetivos foram alcançados. Isto fortalece o entendimento de que existam interesses comerciais envolvidos fantasiados de mensagens inspiradoras.

\subsection{Análise social}

Com apresentação do processo de crítica das representações comunicadas na campanha publicitária \#issomudaomundo, são apresentadas as relações entre as práticas discursivas e as sociais.

Os comerciais sugerem questionamentos sobre a relação com os filhos e as culpas ínsitas, a busca por uma vida mais saudável, o respeito que se tem pelo meio e o resgate de atitudes esquecidas devido às atuais exigências de trabalho. Não se pede que o consumo inexista, mas que mantenha uma relação equilibrada com outros fatores importantes da vida.

A mensagem se distancia do conceito greenwashing, de Dahl (2010), uma denominação adotada para as atividades de divulgação de ações empresariais sem as ações propriamente terem sido feitas. Ao contrário, a instituição financeira pôs em prática várias atividades complementares (Banco Itaú, 2015), como distribuição gratuita de livros didáticos e Olimpíada da Língua Portuguesa (pilar Educação); leitura de livros por famosos, como Maurício de Souza, e distribuição de ingressos para festivais musicais, como o Rock in Rio (pilar Cultura); manual do ciclista e iniciativa das bicicletas laranjinhas junto a prefeituras municipais (pilar Mobilidade Urbana); e patrocínio da Seleção Brasileira e do Miami Open de Tênis (pilar Esporte). Alguns números (Banco Itaú, 2016) que acompanham essas ações demonstram sua dimensão: mais de 45 milhões de livros infantis entregues anualmente, mais de três milhões de espectadores anuais nas salas do Espaço Itaú de Cinema, 400 escolas públicas atendidas pelo programa Jovem com Futuro, financiamento anual aproximado de R $\$ 150$ milhões a microempreendedores e média anual de 13 milhões de acessos ao sítio eletrônico do Itaú Cultural.

Há um aspecto fortemente ligado ao senso comum das pessoas em relação a atividade bancária: banco é o ponto de encontro entre quem tem dinheiro e aquelas que precisam de dinheiro. Os comerciais 
pertencentes à campanha \#issomudaomundo trazem um elemento inesperado, que é o diálogo dessa instituição com os consumidores a respeito da sua vida para além das posses econômicas. $\mathrm{O}$ uso de títulos em forma de uma conversa intimista entre o locutor e o consumidor, tais como "Hoje, você escolhe ir de bike e vê a cidade de um outro jeito" ou "O Itaú apoia escolhas que mudam o seu mundo", facilita o entendimento da importância que o banco quer dar às pessoas. Ao afirmar que as escolhas constroem uma vida, que são elas que diferenciam as opções umas das outras e que há uma instituição que apoia as escolhas que evitam o consumo excessivo, o banco sugere valorizar aspectos de relacionamento entre as pessoas e o que realmente é importante para elas. Isto fica ainda mais patente quando do uso de um título em forma de pergunta ("E você, o que escolhe hoje?"), que aponta claramente para o protagonismo desejado pelas pessoas no direcionamento das suas vidas. Apesar de todo o discurso agradável e notadamente construtivo, é preciso adotar uma leitura com cautela quanto as intenções do anunciante. McCracken (2012) defende que o consumidor contemporâneo tem desenvolvido comportamentos únicos para buscar diferenciação pessoal e construção de uma identidade própria, mas adverte que esse estado pode permitir convencimento mais fácil por meio dos apelos midiáticos.

$\mathrm{O}$ uso de linguagem estética de cinema, com roteiro que cria uma narrativa, é outro argumento utilizado para demonstrar a importância da assunção do conceito de consumo consciente nos dias atuais. As situações apresentadas permitem o uso da imaginação, pois não têm início e fim determinados. O jovem com bicicleta, por exemplo, pode estar indo para a casa de amigos em um fim de semana ou pode estar indo para a biblioteca da universidade, voltando para casa, vindo do apartamento da namorada ou retornando do almoço para o trabalho. Todas são possibilidades que o formato criativo da história permite e que provoca o consumidor a ser partícipe dessa passagem, se vendo na mesma situação ou confirmando algo que faz. É uma linguagem permissiva, que deixa o consumidor dirigir a história, própria do momento em que vivemos. Envolvimento é o que se pretende com a propaganda, basicamente por ela ser a resposta comunicacional da organização aos anseios de determinado grupo de pessoas, conforme o entendimento de Holt (2005). Essa participação do consumidor é absolutamente fundamental para o sucesso da campanha e é esperada pela empresa anunciante.

A comunicação da campanha se vale da compreensão de que a vida deve ser mais do que simplesmente o consumo. Conforme Holbrook e Hirschman (1982), ao consumir a pessoa está em busca de significados para a sua vida. Decorrente do conhecimento anterior da marca (ver Feito Para Você, campanha iniciada em 2004, disponível no repositório Youtube), parece ser uma expectativa natural dos consumidores em relação à instituição. Para Featherstone (1995), um consumidor não adota um estilo de vida de maneira absolutamente irrefletida ou manipulada pela propaganda. O gerenciamento ativo na composição de um estilo de vida, demonstrado pela aquisição de bens, serviços e experiências que tem é dele, consumidor. Também entendem assim Kashdan e Breen (2007), quando defendem que o desejo de possuir novidades em bens e serviços não é independente da cultura e do meio em que vive o consumidor. Os autores sugerem que o contexto familiar, de bairro e de trabalho interferem diretamente no consumo, no gosto e no gasto. Na campanha, seja na forma ou no conteúdo, os comerciais têm apresentado a provocação, a reflexão e uma maneira diferente de pensar em tempos de hiperconsumo.

$\mathrm{Na}$ Tabela 2, são apresentados os principais elementos avaliados com a técnica ACD sobre a campanha \#issomudaomundo, base deste estudo.

Tabela 2 - Principais elementos de análise e contribuições

\begin{tabular}{|c|c|c|}
\hline Tipo de análise & Elementos & Principal contribuição \\
\hline Textual & $\begin{array}{c}\text { Cenas de interação entre pais e } \\
\text { filhos, e o homem e seu meio }\end{array}$ & $\begin{array}{c}\text { Disposição equilibrada entre consumo e } \\
\text { consciência da sociedade para o } \\
\text { fenômeno }\end{array}$ \\
\hline Processual & $\begin{array}{c}\text { Produção de comerciais com } \\
\text { roteiro que permite a imaginação } \\
\text { de novas abordagens, por meio de } \\
\text { metáforas }\end{array}$ & $\begin{array}{c}\text { Protagonismo do espectador no decorrer } \\
\text { das cenas }\end{array}$ \\
\hline Social & $\begin{array}{c}\text { São apresentadas cenas em que se } \\
\text { dá atenção às práticas presentes no } \\
\text { cotidiano das pessoas }\end{array}$ & $\begin{array}{c}\text { O consumidor pode adotar estilo de vida } \\
\text { sem a manipulação pela propaganda }\end{array}$ \\
\hline
\end{tabular}

Fonte: Elaborada pelos autores (2017)

Revista de Gestão Social e Ambiental - RGSA, São Paulo, v. 11, n. 2, p. 73-90, maio/ago. 2017. 


\section{DISCUSSÃO DOS RESULTADOS}

A partir das fases textual, processual e social, previstas na técnica ACD, de Fairclough $(1995 ; 2001)$, foi analisada a campanha \#issomudaomundo e as discussões acerca do consumo e do estilo de vida à luz da proposição de interesses temáticos desenvolvida por Arnould e Thompson (2007).

O primeiro interesse temático de Arnould e Thompson (2007) é denominado de Padrões SócioHistóricos de Consumo (entendimento das estruturas sociais e institucionais que influenciam o consumo, de maneira sistemática, como classe, etnia e gênero).

Neste trabalho, se aborda determinado estrato social, consumidor de ideias que sugere a aquisição de bens ou serviços para a manutenção destas mesmas ideias. Assim, no comercial Educação, Cultura e Bike, a aparição de um jovem utilizando a bicicleta como forma de mobilidade social pressupõe um desembolso para a compra do bem. Diferentemente, porém, da compra como impulso motivado pela propaganda, aqui o significado da aquisição está à frente do ato de compra. A construção dos significados de consumo nos consumidores não é estática, antes revelando a dinâmica social com a qual a relação se envolve. Para McCracken (2003), os responsáveis por esta transferência são a propaganda (do mundo para o bem) e os rituais de consumo (do bem para o indivíduo). Neste sentido, o autor sugere que a função da marca e da propaganda é conectar o mundo culturalmente constituído e os bens, transferindo os significados deste mundo para os bens de consumo e os transformando em significados culturais com a participação do espectador.

Segundo Campbell (2006) e Baudrillard (2009), no início dos anos 1980, época denominada de hipermoderna, consumidores começaram a utilizar mercadorias e marcas para definir sua identidade, embora com comportamentos que demonstravam um afastamento do que ele realmente foi ou desejava ser. $\mathrm{O}$ consumo passou de algo familiar para algo individual. Diferentemente do conceito de pátina, em que bens são passados de pais para filhos, atualmente a prática se dá em consumir bens e serviços que posicionem a pessoa na sociedade. Nos comerciais veiculados, o protagonismo da pessoa é real, pois é ela quem toma atitudes em relação ao conhecimento, quem se relaciona de maneira diferente com a sua vida, e quem faz escolhas que podem mudar o mundo. Indivíduos podem obter o reconhecimento social em grupos, segundo Arnould e Thompson (2007), não pela adoção integral das normas de consumo dos seus membros, mas pela habilidade de adotar de maneira inovadora os significados e os recursos simbólicos do capital cultural desses grupos.

Nesta temática, portanto, as relações de poder a partir das hierarquias socioeconômicas, se dão em duas frentes. A comunicação realizada por uma grande organização, detentora de um espaço de transmissão de ideias como a televisão aberta, a fechada e os repositórios de vídeos, é unilateral. Ou seja, o comando das ações por meio da mídia pertence a apenas um lado. É ele que pode influenciar, enquanto o outro lado, apenas ser influenciado. Lasch (1983) sugere que organizações atuantes em sociedades capitalistas valorizam ideais estritamente consumistas, levando à continuação de sensação de incompletude dos indivíduos. A segunda é a disposição de determinados estratos sociais, notadamente os mais intelectualizados, em adotar comportamentos que levem a significados relevantes para as suas vidas e às atividades conjuntas com os seus grupos. Mostra desta relação de poder é que as locações dos vídeos apresentaram casas, bairros e espaços que passam ao longe do que se pode denominar de modesto. O mesmo autor, Lasch (1983), advoga que mercadorias são divulgadas como sendo uma solução para minimizar descontentamentos, já que indivíduos que apresentam essa condição tendem a se voltar à aquisição de serviços com alto nível de profissionalismo a fim de saciar o problema e buscar alívio. Quando a instituição financeira se desconecta da realidade mediana brasileira ou mostra apenas o cotidiano de indivíduos de alto poder aquisitivo, caracterizado pelas locações em bairros considerados de alto padrão, tende a impor ao consumidor soluções de problemas que não se resolvem somente com o consumo ou estilos de vida que evitariam os problemas de sentimento de vazio ou de angústia. Por outro lado, o anunciante identificou claramente a quem se destinava a comunicação, mais especificamente a que público e com qual tipo de comportamento. Deste modo, o que é preconizado por Arnould e Thompson (2007), quanto aos padrões sócio-históricos de consumo, é identificado, em particular, naquilo que se dá em relação aos grupos e classes envolvidos.

O segundo interesse temático de Arnould e Thompson (2007) é denominado de Culturas de Mercado (maneira como os consumidores criam sentimentos de solidariedade social e constroem mundos culturais diferentes, segmentados e com seleção pessoal, por meio da busca por interesses de consumo comuns).

Em todos os comerciais, as pessoas são questionadas quanto às suas escolhas. Elas podem optar por atividades individuais, como ler um livro, ou atividades coletivas, como ler um livro para os filhos; por uma atividade poluidora, como ir de carro, ou por uma atividade saudável, como ir de bicicleta. Sempre em tom 
amistoso, as mensagens fazem o espectador se questionar sobre as suas atitudes e confirmam que a escolha para a mudança do seu mundo e do mundo dos outros é sua, também. MacInnis e Folkes (2010) afirmam que marcas priorizam ações que, observado o cenário de sensação de vazio expresso pelos indivíduos no momento contemporâneo, se utilizam de sofisticadas técnicas de propaganda para favorecer o consumo como meio de atender a esse sentimento. A confirmar este entendimento, Belk (1988) defende que no conjunto de propostas de consumo e estilos de vida diversos, o consumidor escolhe posições de consumo que se conectem à sua identidade, e que esta escolha se adequa a um modelo de identidade dominante divulgado pela comunicação ao mercado. As organizações, sabedoras de que as pessoas no tempo atual se lançam ao prazer imediato pela compra e uso de produtos e marcas novas, adotam um discurso constante de mudança, de negação ao que não é prazeroso, de busca da eliminação da insegurança. $\mathrm{E}$ o faz isso com o uso de diversas mídias, apresentando novidades e avanços tecnológicos disponíveis para esse indivíduo. Quanto mais poderoso o anunciante, caso de uma instituição financeira, tanto mais possível o uso de ferramentas midiáticas diversas.

Os momentos apresentados no vídeo decorrem de uma forma de vida de indivíduos que não escolheram deixar de consumir, mas consomem de maneira consciente, sem excessos, privilegiando atividades que tragam significado à vida. Há mostra disto no vídeo Educação, Cultura e Bike quando a mãe opta por levar a filha ao balé ao invés de outras práticas mais comuns de convivência entre pais e filhos, como ir ao shopping. Kozinets (2001) defende o uso da denominada cultura de consumo como forma de definir um sistema de imagens, conteúdos e objetos comercialmente produzidos utilizados por grupos, com a construção de práticas e significados interligados ou mesmo conflitantes, como meio de orientar as experiências e a vida dos membros desses grupos. O consumo, portanto, está sempre presente. A diferença é que o consumo com viés consciente representa uma forma de identidade de pessoas que se encontram conectadas com outras pessoas em um mundo visto de maneira diferente por ambas. No entanto, a instituição financeira ora estudada também se usa de artifícios próprios da atividade publicitária para aproximar o perfil hedonista do indivíduo da sua própria proposta comercial. Isto porque o consumidor atual se sente atraído pelos modelos de subjetividade expressos na propaganda, posto que é sensível às ideias de gratificação e segurança, segundo Agrawal e Duhachek (2010).

As situações apresentadas nos comerciais podem ser ou já foram vivenciadas pelo consumidor, facilitando a aceitação das mensagens veiculadas. Este aceite permite a adoção de atitudes positivas e a reverberação destas atitudes por meio das redes sociais. Para Solomon (2008), as pessoas podem ser classificadas em grupos conforme as atividades de que fazem parte: como gastam a renda disponível e de que forma gostam de usar o seu tempo livre. Isto gera um diálogo entre a organização anunciante e o espectador cuja identidade tenha proximidade com as mensagens dos comerciais. Para McCracken (2012), o consumidor é livre para definir o significado que quer dos produtos que consome e pela capacidade de readequar padrões culturais em processos de apropriação durante as interações sociais para a construção de sua identidade. É nesta transferência que se revela a importância de agentes intermediadores como a marca que, segundo Featherstone (1995), comunica significados que emergem da sociedade e permitem a fusão dos produtos anunciados com a representação do mundo.

Nesta segunda temática, portanto, as dinâmicas socioculturais das comunidades de marca, principalmente as tribos que têm o mercado como mediador das suas relações, foram abordadas. Apresentando cenas de famílias ocupadas com o aprendizado, jovens imbuídos de ideais de vida mais equilibrados e pessoas conscientes da sua responsabilidade no convívio social, a marca reverbera o anseio de grupos de pessoas que buscam um mundo diferente culturalmente, com a adoção do consumo consciente. Fica patente, porém, que a instituição anunciante se utiliza da riqueza de ferramentas para convencimento que a propaganda permite para discorrer exatamente sobre a mensagem e os signos que importam ao espectador.

O terceiro interesse temático de Arnould e Thompson (2007) é denominado de Ideologias do Mercado Midiático de Massas e Estratégias Interpretativistas dos Consumidores (arcabouços de significados ideológicos que levam à vazão e à reprodução de pensamentos e ações para a defesa dos interesses dominantes da sociedade).

O consumo simbólico é determinante em um mercado que supera a antiga lógica de produção e venda, ao sugerir conceitos de estilo de vida. Uma das maneiras mais intensas de interpelação pela cultura de consumo é a propaganda, conforme Featherstone (1995). Para o autor, ela opera por meio de um trabalho consistente com signos retirados de um espaço de conotação determinado arbitrariamente por sua posição, em um conjunto que é autorreferenciado de significantes constituídos socialmente. Este formato, segundo Featherstone (1995), confere tanto ao consumidor quanto ao bem de consumo uma identidade social 
concreta. Os consumidores usam significados de marcas e de bens de consumo com objetivos culturais, segundo McCracken (2003), quando criam e sustentam estilos de vida, constroem noções de si mesmo e se definem coletivamente ao tornar o consumo responsável pela estruturação de uma realidade atual. Neste sentido, o consumo pode ser considerado um ato muito além da simples ostentação, sendo uma prática cultural e identitária que satisfaz necessidades fisiológicas e psicológicas e comunica algo para os diversos grupos.

Os valores contidos na propaganda do Itaú estão enraizados na cultura contemporânea, como o relacionamento familiar, o viver saudável e a ampliação do conhecimento, e isto aumenta a capacidade de reconhecimento positivo da marca anunciante. E o banco se apropria de um discurso pronto e assumido pelo indivíduo para valorizar a sua própria marca. Anteriormente, marcas identificavam um produto por sua utilidade. Agora, conferem ao bem ou serviço um forte peso simbólico, assumindo a condição de canais de autoexpressão pelos quais o consumidor constrói a sua identidade. Para Holt (2005), marcas podem ser consideradas como elementos que contribuem diretamente com a construção da identidade dos consumidores, por meio de significados culturais relevantes.

Os comerciais analisados, por meio de situações simples, como a ida ao cinema ou a leitura de um livro para os filhos, sugerem elevar a marca a um nível bastante próximo do consumidor, de tal maneira que as mensagens se configurem em diálogos agradáveis e prazerosos. Holt (2005) defende que, no cenário contemporâneo, a marca atua na transformação da cultura e da sociedade e, neste processo, além de produzir significados, comunica expressões culturais para promover tais transformações. Segundo Arnould e Thompson (2007), a cultura de consumo e as ideologias impostas pelo mercado estimulam os consumidores ao impor regras e restrições transmissoras de concepções que criam plataformas para determinados padrões de comportamento e de tomada de decisões de compra. A instituição financeira, apoiada pela expertise da agência de comunicação, tem ciência de que as condições de vida do sujeito hipermoderno estimulam o consumo. Este comportamento, no entender de Toomey e Francis (2013), é incentivado pelo perfil hedonista de uma época denominada hipermoderna, com estilo de vida cujo prazer deve ser vivido com grande intensidade e frequência, sem esforços demasiados. Levar às telas de TVs e computadores, portanto, cenas que dialoguem com as crenças cotidianas desse indivíduo facilita o surgimento de posturas que indiretamente incentivem o consumo.

Propaganda geralmente é vista pela sua função convencional de levar à ação de compra, promovendo vantagens e divulgando benefícios do bem ou do serviço. Nos comerciais analisados, há evidências de que a intenção foi outra. Ainda que a cor alaranjada que identifica o anunciante esteja presente em muitas cenas, em nenhum momento se procede ao convite à aquisição de serviços da instituição ou de qualquer outra empresa. Para Holt (2005) a abordagem tradicional da propaganda desconsidera o contexto cultural do consumo, ao ignorar que aquele indivíduo que processa a informação está imerso em um ambiente altamente constituído por significados, envolto por uma natureza cultural coletiva. Os comerciais da campanha \#issomudaomundo trazem à tona valores que, de maneira simples, podem alterar o cotidiano individual, em seguida de um grupo de pessoas e, depois, de todos. O consumidor da era hipermoderna adota comportamentos individualistas como forma de diferenciação. Para Baudrillard (2009), porém, é por meio de interações sociais que as características pessoais são moldadas e estas, ao longo de um tempo, definem o estilo que dirigirá os hábitos de consumo do indivíduo

A propaganda permite à cultura moderna um espaço para experimentação onde se fabricam novos significados culturais e se revitalizam os antigos. Ela é vista como uma fonte de significados para os consumidores, que identificam a necessidade de completar a sua vida com determinados produtos (bens ou serviços) e suas características anunciadas. Ao resgatar hábitos simples, como a leitura para os filhos em um sábado pela manhã ou a ida ao cinema, a campanha revitaliza conheceres familiares e introduz novos entendimentos sobre atividades corriqueiras, mas às vezes não praticadas. Para McCracken (2003), a atividade da propaganda é um instrumento de transferência de significado, um canal por onde a dinâmica do significado é constante e onde produtos novos e antigos adotam significados diferentes. O consumidor, porém, se sente atraído a aderir a modelos de subjetividade expressos na comunicação midiática, uma vez que a ideia de segurança presente nas histórias contadas na propaganda lhe é bastante satisfatório. Um comercial de banco, por menor que seja a sua intenção em vender algum bem ou serviço, sugere determinadas condições que minimizam a capacidade de análise de consumidores ávidos por uma identidade que prorrogue a sensação de estar bem.

$\mathrm{Na}$ abordagem da terceira temática, em que as representações ideológicas do consumismo sugerem o uso midiático ativo, a influência de comportamentos globalizados na mídia leva ao consumo seletivo por pessoas cujo ideal de vida passa pelo não consumismo e pela adoção de atividades que sejam benéficas ao 
meio. Os dois comerciais expressaram representações discursivas e imagéticas, com cenas repletas de possibilidades de interpretação pelas pessoas, e todas representando um modo de vida cujo consumo existe e é consciente.

O quarto interesse temático de Arnould e Thompson (2007) tem o título de Projetos de Identidade do Consumidor (o mercado é uma fonte de recursos sígnicos e míticos, por meio dos quais são vividas narrativas para a construção da identidade).

A campanha \#issomudaomundo apresenta um repensar sobre as atividades de significação das marcas, propaganda e do modelo de análise daquilo que o consumidor recebe como comunicação da organização. O refinamento da dinâmica de comunicação do consumidor, com o uso de múltiplas plataformas, muitas vezes usadas simultaneamente, eleva o patamar em que a empresa anunciante tem que se posicionar, exigindo ajustes dos processos internos rumo aos significados individuais e sociais exigidos por esse novo consumidor.

O movimento do consumo consciente, em que pequenos gestos realizados por um grande número de pessoas podem promover transformações, dá relevo às mensagens veiculadas e atende a um público que já não se contenta com o consumo como um ato isolado. McCracken (2003) entende o consumo como maneira de encontrar respostas para a construção identitária e não para intensificar os efeitos de uma crise de identidade. Sob esse enfoque, o autor caracteriza o consumo como um ato de "ser", com as pessoas consumindo em busca de significado para a sua vida, propiciado pelo conhecimento de si mesmas.

Isto pressupõe que o consumidor seja integrante da construção dos significados das aquisições e, para além da propaganda, que a marca seja partícipe deste processo. Campbell (2006) sugere que a atividade de comprar não é só um meio pelo qual as pessoas descobrem quem são. Também fornece a elas a comprovação básica de sua existência. Esse fato, não significa, necessariamente, que a identidade deriva de um bem ou serviço consumido, nem que as pessoas são aquilo que consomem. A identidade está nas relações com os produtos, por meio das suas marcas. Embora a propaganda estudada não tenha dado relevo a nenhum produto, consegue valorizar a marca fortemente, seja pelos elementos sígnicos, especialmente a cor, ou pelo raciocínio criativo utilizado, trazendo cenas do dia a dia para valorizar uma ideia. Aparentando ser uma contradição própria do momento contemporâneo, o esforço de comunicação em estudo é referente ao encontro de prazer emocional de diferentes espécies, mas que só pode ser propiciado pela aquisição de algum produto. Ou seja, embora a linguagem utilizada pareça ser clara e objetiva, pode estar mascarando intenções mercantilistas. Ainda que o indivíduo possa apresentar um desejo considerável por individualidade e consumo consciente, estando movido a tomar parte em atos criativos de expressão, podem suas ações serem dirigidas a algum tipo de consumo tradicional. Para Kozinets (2001) e Solomon (2008), a acumulação de significados, rituais e tradições, quando compartilhadas pelos membros de um grupo, é um importante fator de delimitação de desejos e comportamentos.

Este raciocínio trata o consumidor como alguém situado em determinado contexto e dedicado a algo, ambos culturalmente constituídos. Para McCracken (2012), ele é visto pela busca constante de informações e de significados ínsitos na propaganda e que satisfazem aos seus anseios como pessoa envolvida em um contexto cultural. Se para Belk (1988) a cultura de consumo, as preferências e as posses podem apresentar um sentido individual ou expressar um sentimento de pertencimento e identidade de grupo, então as atividades apresentadas nos comerciais são atividades de consumo, ainda que não obrigatoriamente de bens ou de serviços vendidos por um anunciante. Campbell (2006) argumenta, em contraponto, que teorias pósmodernas afirmam ser o sujeito contemporâneo um elemento desprovido de um conceito fixo e que usaria a vasta oferta de novidades para recriar a si mesmo, trocando constantemente de identidade e de estilo de vida, isso, no entanto, não implica que as pessoas talvez não estejam se afastando da sua interioridade, uma vez que o consumo não substitui algum comportamento humano similar. O que ele pode auxiliar é compensar algo não vivido.

Nesta abordagem da quarta temática, em que as atividades de identidade, imagem e representação do Eu são consolidadas, as dimensões experienciais do consumo se apresentaram latentes nas iniciativas de comunicação do anunciante. Na valorização de pequenas vitórias que se transformam em grandes conquistas, como na cena envolvendo o balé, a filha e a mãe, ou quando há a incorporação de um herói pelo menino, na cena que descreve o garoto e o cinema, são expressos fortemente elementos que condizem com o conceito de experiência, da valorização dos pequenos e dos grandes gestos, e da ação que pode ser muito importante emocionalmente para uma pessoa ainda que seja irrelevante para outra. Abordagens como estas minimizam conflitos existentes entre experiências de consumo e comportamento de compra, pois os indivíduos conseguem, levando em consideração a miscelânea de estilos e modismos contemporâneos, manifestar a sua identidade com um estilo próprio de consumir. Ao mesmo tempo, ampliam a dependência em relação a 
propaganda e aos estilos nela sugeridos, o que gera um ser cuja individualidade se perde, ainda que ele não compreenda assim, embaçada que está a sua visão pelos artifícios publicitários utilizados.

Este trabalho, portanto, ao analisar situações em que as pessoas participam ativamente e demonstram a sua identidade de consumidores não consumistas, antes ocupadas com situações relevantes para a sua vida e para as dos grupos com os quais convive, confirma que a campanha \#issomudaomundo tem conexão com o conceito de consumo consciente.

Os interesses temáticos de Arnould e Thompson (2007), que, para os autores, formam a CCT, se mostraram presentes na campanha estudada, principalmente os aspectos que se referem aos signos, a construção de identidade e aos significados ideológicos. Esta presença é importante elemento de confirmação de que mesmo em um tipo de propaganda desprovido de interesses comerciais diretos, os aspectos aderentes à cultura de consumo encontram espaço de atuação.

$\mathrm{Na}$ Tabela 3, a seguir, são apresentados os principais achados deste estudo sobre a relação entre a CCT e o conteúdo das mensagens, a partir da campanha '\#issomudaomundo', base deste estudo.

Tabela 3 - Conexões entre a CCT e o conteúdo das mensagens da propaganda estudada

\begin{tabular}{|c|c|c|c|}
\hline $\begin{array}{c}\text { Interesse temático da } \\
\text { CCT }\end{array}$ & $\begin{array}{l}\text { Ações presentes na } \\
\text { campanha estudada }\end{array}$ & $\begin{array}{l}\text { Conexão dos interesses } \\
\text { temáticos com os } \\
\text { elementos da propaganda }\end{array}$ & $\begin{array}{c}\text { Principais autores } \\
\text { usados na discussão dos } \\
\text { resultados }\end{array}$ \\
\hline $\begin{array}{l}\text { Padrões sócio-históricos } \\
\text { de consumo }\end{array}$ & $\begin{array}{c}\text { Comercial Educação, } \\
\text { Cultura e Bike; jovem com } \\
\text { bicicleta como forma de } \\
\text { mobilidade; locações de } \\
\text { residências que } \\
\text { determinam o padrão do } \\
\text { morador }\end{array}$ & $\begin{array}{l}\text { Estruturas sociais de classe; } \\
\text { relação de poder; } \\
\text { hierarquias } \\
\text { socioeconômicas }\end{array}$ & $\begin{array}{l}\text { Arnould e Thompson } \\
\text { (2007); McCracken } \\
\text { (2003); Lasch (1983) }\end{array}$ \\
\hline Culturas de mercado & $\begin{array}{c}\text { Comercial Educação, } \\
\text { Cultura e Bike; comercial } \\
\text { Suas escolhas; leitura de } \\
\text { livro para os filhos; filha } \\
\text { no balé; uso da bicicleta } \\
\text { como forma de mobilidade }\end{array}$ & $\begin{array}{l}\text { Construção de mundos } \\
\text { diferentes; interesses de } \\
\text { consumo comuns; valores } \\
\text { fundamentais; dinâmicas } \\
\text { socioculturais das marcas }\end{array}$ & $\begin{array}{c}\text { Arnould e Thompson } \\
\text { (2007); Belk (1988); } \\
\text { Kozinets (2001); Holt } \\
\text { (2005) }\end{array}$ \\
\hline $\begin{array}{l}\text { Ideologias do mercado } \\
\text { midiático de massa e } \\
\text { estratégias } \\
\text { interpretativas dos } \\
\text { consumidores }\end{array}$ & $\begin{array}{c}\text { Comercial Educação, } \\
\text { Cultura e Bike; comercial } \\
\text { Suas Escolhas; ida ao } \\
\text { cinema; leitura de livro } \\
\text { para os filhos; cenas } \\
\text { urbanas com a cor do } \\
\text { anunciante como pano de } \\
\text { fundo }\end{array}$ & $\begin{array}{l}\text { Representações discursivas } \\
\text { e imagéticas; globalização } \\
\text { no consumo; ações em } \\
\text { defesa dos interessantes da } \\
\text { sociedade }\end{array}$ & $\begin{array}{l}\text { Arnould e Thompson } \\
\text { (2007); Featherstone } \\
\text { (1995); McCracken } \\
\text { (2003); Holt (2005) }\end{array}$ \\
\hline $\begin{array}{l}\text { Projetos de identidade } \\
\text { do consumidor }\end{array}$ & $\begin{array}{l}\text { Comercial Educação, } \\
\text { Cultura e Bike; comercial } \\
\text { Suas Escolhas; filha no } \\
\text { balé; ida ao cinema }\end{array}$ & $\begin{array}{l}\text { Narrativas que apoiam a } \\
\text { construção de identidade; } \\
\text { imagem do Eu; recursos } \\
\text { sígnicos; dimensões } \\
\text { experienciais do consumo }\end{array}$ & $\begin{array}{c}\text { Arnould e Thompson } \\
\text { (2007); McCracken } \\
\text { (2012); Solomon (2008) }\end{array}$ \\
\hline
\end{tabular}

Nota. Fonte: autores (2016).

\section{CONSIDERAÇÕES FINAIS}

Este artigo relata os resultados de um estudo que buscou refletir, com base em experiências reais, sobre a comunicação do conceito de consumo consciente de uma grande organização e o distanciamento ou a proximidade com os conceitos gerais da cultura de consumo das pessoas. $\mathrm{O}$ que se pretendeu foi, à luz do entendimento de Arnould e Thompson (2007) para aspectos relacionados à cultura do consumo, elaborar contribuições a respeito do crescente movimento de consumo consciente.

Os movimentos de consciência, construídos pelas organizações contemporâneas como um discurso adequado aos novos tempos e adotados pelas pessoas como uma atitude positiva, começam a se tornar mais presentes na vida cotidiana. Embora as organizações tenham como meio de sobrevivência a obtenção de lucro e, portanto, o consumo seja absolutamente basilar para a atividade, o estilo de vida com consumo 
desenfreado, sustentado pela riqueza de bens materiais parou de contribuir significativamente para o bemestar individual na sociedade. A cultura de consumo tem comprometido diversos fatores dos quais este bemestar depende, tais como o convívio com os seus e a comunidade, o equilíbrio entre as esferas do campo social e do profissional, e uma vida espiritual saudável.

A busca pelo envolvimento de pessoas com ideais de consumo consciente parece ser o maior objetivo da instituição anunciante na campanha analisada. O conteúdo da mensagem da propaganda do banco sugere ser possível melhorar a vida das pessoas e auxiliar a sociedade a adotar valores importantes, além daqueles obtidos exclusivamente pela satisfação com a compra de bens e serviços. O pano de fundo é a capacidade de as pessoas absorverem novas atitudes, assumindo o consumo consciente ao invés do consumismo. De um lado, se tem evidenciado o interesse temático referente às Ideologias de mercado midiático, segundo Arnould e Thompson (2007), com as ações mercadológicas adotadas ocorrendo em defesa dos interesses da sociedade. De outro, foram apresentadas narrativas que apoiam a construção da identidade do indivíduo.

A inserção da discussão sobre o consumo consciente na campanha publicitária atende aos interesses temáticos Culturas de mercado e Projetos de identidade do consumidor, de Arnould e Thompson (2007). Enquanto apresenta os interesses de consumo comuns das pessoas envolvidas e a possível construção de mundos diferentes, também buscou apresentar recursos sígnicos da marca e das situações, além de narrativas que contribuem para a identidade dos envolvidos.

É mister salientar que, a despeito do esforço de comunicação apresentar considerações francamente dirigidas ao consumo consciente, a instituição financeira anunciante se defronta com iniciativas bastante invasivas. Ao tentar se valer de um momento contemporâneo de recriação de valores internos das pessoas como mote da campanha publicitária, acaba cometendo um certo exagero na mensagem. As sensações possivelmente ilusórias provocadas pela comunicação (de compensação por algo não vivido ou de facilitação da expressão de sentimentos identitários), são as mesmas divulgadas pela propaganda que evoca sentimentos positivos intermediados pelos bens que são consumidos, mas com outra roupagem.

Embora exista uma lacuna na literatura de Marketing sobre como as expectativas das pessoas em relação a uma sociedade sustentável surgem e de que maneira são mantidas, algumas organizações, de maneira deliberada, assumem os riscos da comunicação CSR ao se envolverem em projetos de cunho social, artístico, literário, esportivo e de lazer. Ainda assim, é necessário se colocar a distância para observar o fenômeno comunicacional divulgado pela instituição financeira, sob pena de se envolver na história contada e não perceber que pouco se altera da comunicação comercial convencional, a não ser a maneira com que a mensagem é contada.

À luz do entendimento de Arnould e Thompson (2007) e o esquema com quatro interesses temáticos (padrões sócio-históricos de consumo, culturas de mercado, ideologias do mercado midiático e projetos de identidade do consumidor), as ações de propaganda com apelo de consumo consciente da organização estudada demonstram que a competitividade do segmento não impede que ações desse teor sejam realizadas.

\subsection{Implicações acadêmicas}

Os achados contribuem para amplo espectro de discussões acadêmicas voltadas à diretriz básica da propaganda e da significação das mensagens comunicadas, assim como do consumo consciente, permitindo abordagens para estudo e ensino em disciplinas como Marketing, Branding e Estratégias de Marketing. A intenção não é esgotar as análises, posto que estão em curso outras ações de propaganda dessa natureza. É, essencialmente, um exercício acadêmico e gerencial para refletir sobre entidades que, a priori, só sobrevivem com alto consumo, mas que divulgam outros estilos de vida, voltados ao consumo consciente. Futuras pesquisas podem explorar as limitações deste artigo, basicamente ser um estudo de caso único e sua decorrente ausência de comparações com a propaganda de consumo consciente de outras instituições financeiras, ou proceder análise de resultados obtidos por organizações com campanhas semelhantes, a partir do que preconiza a CCT.

\section{NOTA}

Este trabalho tem o apoio da Fundação de Apoio à Pesquisa e Inovação do Estado de Santa Catarina (Fapesc) e da Associação Catarinense das Fundações Educacionais (Acafe). 


\section{REFERÊNCIAS}

Agrawal, N., \& Duhachek, A. (2010). Emotional compatibility and the effectiveness of antidrinking messages: a defensive processing perspective on shame and guilt. Journal of Marketing Research, 47(2), 263-273.

Arnould, E., \& Thompson, C. (2005). Consumer culture theory (CCT): twenty years of research. Journal of Consumer Research, 31(4), 868-882.

Arnould, E., \& Thompson, C. (2007). Consumer culture theory (and we really mean theoretics): dilemmas and opportunities posed by an academic branding strategy. In: Belk, R. W, \& Sherry Jr, J. F. (eds). Research in Consumer Behaviour, 3-22. Oxford: Elsevier.

Askegaard, S., \& Linnet, J. (2011). Towards an epistemology of consumer culture theory: Phenomenology and the context of context. Marketing Theory, 11(4), 381-404.

Baudrillard, J. (2009). A sociedade de consumo. Lisboa: Edições 70.

Bauman, Z. (2001). Modernidade líquida. Rio de Janeiro: Jorge Zahar.

Belk, R. (1988). Possessions and the extended self. Journal of Consumer Research, 15(2), 139-168.

Bridges, S., Keller, K. L., \& Sood, S. (2000). Communication strategies for brand extensions: Enhancing perceived fit by establishing explanatory links. Journal of Advertising, 29(4), 1-11.

Campbell, C. (2006). Eu compro, logo sei que existo: as bases metafísicas do consumo moderno, p. 47-64. In Barbosa, L., \& Campbell, C. (org.). Cultura, Consumo e Identidade. São Paulo: Editora FGV.

Chouliaraki, L., \& Fairclough, N. (1999). Discourse in late modernity: rethinking critical discourse analysis. Edinburgh, Edinburgh University Press.

Cross, G. (2000). The irony of the century. In: An All-Consuming Century: why commercialism won in modern America. New York: Columbia University Press.

Dahl, R. (2010). Greenwashing: do you know what you're buying?. Environmental Health Perspectives, $118(6)$, A246-A252.

Dolbec, P., \& Fischer, E. (2015). Refashioning a field? Connected consumers and institutional dynamics in markets. Journal of Consumer Research, 41(6), 1447-1468.

European Commision. (2014). A renewed EU strategy 2011-14 for corporate social responsibility. Retrieved from http://eur-lex.europa.eu/LexUriServ/LexUriServ.do?uri=COM:2011:0681:FIN:en:PDF

Fairclough, N. (1995). Critical discourse analysis: the critical study of language. London: Longman.

Fairclough, N. (2001). Discurso e mudança social. Brasília: Ed. Universidade de Brasília.

Featherstone, M. (1995). Cultura de consumo e pós-modernismo. São Paulo: Studio Nobel.

Fournier, S. (1998). Consumer and their brands: developing relationship theory in consumer research. Journal of Consumer Research, 24(4), 343-373.

Holbrook, M. B., Hirschman, E. C. (1982). The experiential aspects of consumption: consumer fantasies, feelings, and fun. Journal of Consumer Research, 9(2), 132-140.

Holt, D. B. (2005). Como as marcas se tornam ícones: os princípios do branding cultural. São Paulo: Ed. Cultrix.

Kalra, A., \& Soberman, D. (2010). The forgotten side of marketing. Brand Management, 17(4), 301-314.

Kashdan, T. B., \& Breen, W. E. (2007). Materialism and diminished well-being: experiential avoidance as a mediating mechanism. Journal of Social and Clinical Psychology, 26(1), 521-539.

Kozinets, R. (2001). Utopian enterprise: articulating the meaning of Star Trek's culture of consumption. Journal of Consumer Research, 28(2), 67-89.

Lasch, C. (1983). A cultura do narcisismo. Rio de Janeiro: Imago. 
Levy, S. J. (1981). Interpreting consumer mythology: a structural approach to consumer behavior. Journal of Marketing, 45(3), 49-61.

MacInnis, D. J., \& Folkes, V. S. (2010). The disciplinary status of consumer behavior: a sociology of science perspective on key controversies. Journal of Consumer Research, 36(6), 899-914.

Magalhães, C. M. (2001). A análise crítica do discurso enquanto teoria e método de estudo, pp. 15-30. In Magalhães, C. M. (org.) Reflexões sobre a análise crítica do discurso. Belo Horizonte: Faculdade de Letras, UFMG.

Malhotra, N. (2010). Marketing research: an applied orientation. New Jersey/USA: Prentice Hall.

McCracken, G. (2003). Cultura \& Consumo: novas abordagens ao caráter simbólico dos bens e das atividades de consumo. Rio de Janeiro: Mauad.

McCracken, G. (2012). Cultura \& Consumo II: mercados, significados e gerenciamento de marcas. Rio de Janeiro: Mauad.

McWilliams, A., \& Siegel, D. (2001). Corporate social responsibility: a theory of the firm perspective. Academy of Management Review, 26(2), 117-127.

Miles, M. B., \& Huberman, A. M. (1994). Qualitative data analysis: an expanded sourcebook. London: Sage Publications.

Miller, D. (1995). Pobreza da moralidade. Antropolítica: Revista Contemporânea de Antropologia e Ciência Política, 1(2), 123-135.

Morgan, F., \& Stoltman, J. (2002). Television advertising disclosures: an empirical assessment. Journal of Business and Psycology, 16(4), 515-535.

Morgan, G. (2011). Imagens da organização. São Paulo: Atlas.

Morsing, M. (2006). Corporate social responsibility as strategic auto-communication: On the role of external stakeholders for member identification. Business Ethics: A European Review, 15(2), 171-182.

Nair, S., \& Ndubisi, N. O. (2011). Stakeholder influences on environmental marketing. Journal of Management Research, 11(2), 67-76.

Prasad, A., \& Holzinger, I. (2013). Seeing through smoke and mirrors: a critical analysis of Marketing CSR. Journal of Business Research, 66(3), 1915-1921.

Scharf, E. R., \& Sarquis, A. B. (2014). Análise crítica do discurso na propaganda de lançamento do Citröen C3 Picasso. Revista Brasileira de Marketing, 13(3), 36-48.

Skarmeas, D., \& Leonidou, C. N. (2013). When consumers doubt, watch out! The role of CSR skepticism. Journal of Business Research, 66(3), 1831-1838.

Slater, D. (2001) Cultura do consumo \& modernidade-Exame. NBL Editora.

Solomon, M. (2008). O comportamento do consumidor: comprando, possuindo e sendo. Porto Alegre: Bookman.

Toomey, D. A., Francis, A. L. (2013). Branded product placement and pre-teenaged consumers: influence on brand preference and choice. Young Consumers, 14(2), 180-192.

Whiting, A., \& Williams, D. (2013). Why people use social media: a uses and gratifications approach. Qualitative Market Research: An International Journal, 16(4), 362-369. 
Data da submissão: 21/02/2017

Data de aceite: $28 / 08 / 2017$

Revista de Gestão Social e Ambiental - RGSA, São Paulo, v. 11, n. 2, p. 73-90, maio/ago. 2017. 